\title{
A protein semisynthesis-based strategy to probe the impact of site-specific serine ADP- ribosylation on linker histone function
}

By Kyuto Tashiro ${ }^{1}$, Jugal Mohapatra ${ }^{1}$, Chad A. Brautigam² ${ }^{2}$ and Glen Liszczak ${ }^{1, *}$

${ }^{1}$ Department of Biochemistry, University of Texas Southwestern Medical Center, 5323 Harry

Hines Boulevard, Dallas, TX 75390-9038, USA

${ }^{2}$ Departments of Biophysics and Microbiology, University of Texas Southwestern Medical

Center, 5323 Harry Hines Boulevard, Dallas, TX 75390-9038, USA

*correspondence: glen.liszczak@utsouthwestern.edu 
1 Abstract: Recently developed chemical and enzyme-based technologies to install serine ADP-

2 ribosylation onto synthetic peptides have enabled new approaches to study PARP biology.

3 Here, we establish a generalizable strategy to prepare ADP-ribosylated peptides that are

4 compatible with $\mathrm{N}$-terminal, $\mathrm{C}$-terminal and sequential protein ligation reactions. Two unique

5 protein-assembly routes are employed to generate full-length linker histone constructs that are

6 homogenously ADP-ribosylated at known DNA damage-dependent modification sites. We found

7 that serine mono-ADP-ribosylation is sufficient to alleviate linker histone-dependent chromatin

8 compaction, and that this effect is amplified by ADP-ribose chain elongation. Our work will

9 greatly expand the scope of ADP-ribose-modified proteins that can be constructed via

10 semisynthesis, which is rapidly emerging as a robust approach to elucidate the direct effects

11 that site-specific serine mono- and poly-ADP-ribosylation have on protein function.

13 Protein ADP-ribosylation (ADPr) is an $\mathrm{NAD}^{+}$-dependent post-translational modification that

14 targets hundreds of proteins in mammalian cells to regulate diverse signaling processes ${ }^{1}$.

15 Among the most widespread forms of this modification is DNA damage-induced serine ADPr,

16 which is catalyzed by the PARP1/2:HPF1 complex ${ }^{2-5}$. While intense efforts have been directed

17 towards understanding PARP1/2:HPF1 regulatory mechanisms ${ }^{6-8}$, substrate preferences ${ }^{4,9,10}$,

18 and factors that govern ADP-ribose chain elongation ${ }^{11-13}$ many questions remain surrounding

19 how specific mono- and poly-ADPr events affect target protein function. A greater understanding

20 of ADPr-mediated signaling mechanisms could expand the effective use of PARP1/2 inhibitors

21 for the treatment of homology repair-deficient cancers and other diseases ${ }^{14}$, and has the

22 potential to uncover alternative treatment strategies.

24 We and others recently developed synthetic and chemoenzymatic strategies to prepare

25 peptides bearing site-specific serine $\operatorname{ADPr}^{12,15,16}$. These approaches are compatible with peptide

26 thioesters to enable native chemical ligation, which is a cornerstone of protein post-translational 
modification research that can now be applied to the study of serine ADPr. However, the core histones $\mathrm{H} 2 \mathrm{~B}$ and $\mathrm{H} 3$ remain the only two full-length, serine ADP-ribosylated proteins that have been assembled via semisynthesis ${ }^{12,17}$. Notably, both $\mathrm{H} 2 \mathrm{~B}$ and $\mathrm{H} 3$ were prepared via a single ligation reaction wherein the ADP-ribosylated N-terminal peptide thioester fragment was ligated to a recombinant C-terminal fragment. More modular functionalization of ADP-ribosylated peptides, including an $\mathrm{N}$-terminal cysteine and a latent $\mathrm{C}$-terminal thioester, is necessary to grant access to modification sites throughout an entire protein sequence. This design would vastly expand the number of semisynthetically modified PARP1/2:HPF1 substrates that can be functionally characterized in biochemical, biophysical, and cell-based assays.

The disordered, lysine-rich $\mathrm{C}$-terminal domain of linker histone $\mathrm{H} 1$ contains several serine residues that act as acceptor sites for DNA damage-induced $\operatorname{ADPr}^{4,8,9,18}$. It is clear that PARP1/2 activity is required to release linker histone $\mathrm{H} 1$ from chromatin at DNA damage sites, which contributes to local chromatin relaxation and DNA repair ${ }^{18,19}$. Multiple mechanisms to explain how PARP1 activity impacts $\mathrm{H} 1$ function have been put forth, including: (i) PARP1 displaces H1 from chromatin by engaging an overlapping nucleosome binding site, (ii) a non-covalent $\mathrm{H} 1$ :poly-ADPr interaction disrupts the H1:DNA interface, and (iii) poly-anionic ADP-ribose chains reduce the affinity between the highly basic $\mathrm{H} 1 \mathrm{C}$-terminus and the negatively charged chromatin polymer ${ }^{19-22}$. Additionally, H1 ADPr may induce downstream protein-modification cascades or ADP-ribose-binding protein recruitment events that influence $\mathrm{H} 1$ function. With semisynthetic ADP-ribosylated $\mathrm{H} 1$ constructs, chromatin structure analysis can be performed in the absence of confounding variables that include the PARP1 enzyme, core histone ADPr, and other protein modifications or DNA repair factors. Thus, the impact that site-specific mono- and poly-ADPr have on $\mathrm{H} 1$ function can be directly interrogated. 
52 We chose to study the linker histone $\mathrm{H} 1.2$ as it is an abundant variant and a known target of 53 DNA damage-induced serine ADPr ${ }^{8,18}$. There are four PARP1/2:HPF1 substrate motifs (Lys-

54 Ser) in $\mathrm{H} 1.2$ (Figure 1A), of which several have been reported as ADPr acceptor sites in

55 mammalian cell-based assays. To determine the primary H1.2 ADPr sites, we introduced wild-

56 type or serine-to-alanine 6xHis-tagged H1.2 transgenes into HEK293T cells for ADPr analysis.

57 Following exposure to an oxidative DNA damage agent, cells were collected and lysed in a

58 denaturing buffer that included 6M urea to rapidly quench all ADPr and glycohydrolase activity.

59 Lysates were then cleared and passed over an Ni-NTA column to enrich $\mathrm{H} 1.2$ transgenes for

60 western blot analysis (Figure 1B). We found that all detectable H1.2 ADPr occurs at the S150

61 and S188 sites, as confirmed by the S150A/S188A double mutant. This modification site

62 preference is also maintained in reconstituted ADPr assays comprising the PARP1/2:HPF1 complex and recombinant, full-length H1.2 constructs (Figure 1C). While the S86 site falls within the folded domain of H1.2 and is likely sterically protected from PARP1 activity, the S150, S173 and S188 sites are located within the C-terminal disordered region. Unlike S150 and S188, the S173 site is immediately followed by a proline residue, which we hypothesized may prevent modification by the PARP1:HPF1 complex. To test this concept, an RP-HPLC/MS-based assay was employed to analyze PARP1:HPF1 activity on $\mathrm{H} 1.2$ peptide fragments (Figure 1D, Figure S1). Indeed, while ADPr could not be detected on the H1.2 ${ }_{166-181}$ fragment, the H1.2 $143-158$, H1.2 ${ }_{182-195}$, and an H1.2 ${ }_{166-181}$ bearing a P174A mutation were quantitatively ADP-ribosylated after a 20 minute incubation with PARP1:HPF1 $(1 \mu \mathrm{M}: 25 \mu \mathrm{M})$ at $30^{\circ} \mathrm{C}$. Thus, a proline residue

72 C-terminal to the Lys-Ser motif potently inhibits PARP1:HPF1 activity.

With key H1.2 serine ADPr target sites established, we set out to prepare semisynthetic $\mathrm{H} 1.2$

75 constructs modified with mono-ADP-ribose at the S150 or S188 site. We envisioned a three- 
intein fusion-based approach and a recombinant piece 3 fragment (amino acids 163-213, A163C; H1.2163-213) was prepared via standard procedures (Figure S2). The synthetic piece 2 fragment (amino acids 142-162, A142C; H1.2 142-162) was initially functionalized with an Nterminal cysteine and a C-terminal acyl hydrazide, which can be converted to a thioester in a biorthogonal reaction ${ }^{23}$ to enable sequential protein ligations starting from the $\mathrm{N}$-terminus. Following peptide synthesis, H1.2 ${ }_{142-162}$ was incubated with the PARP1:HPF1 complex in the presence of PARG to install the mono-ADP-ribose modification at S150, the sole serine residue in the peptide. However, post-reaction analysis revealed that the $\mathrm{H} 1.2_{142-162}$ fragment is modified with two ADP-ribose moieties, and a similar peptide substrate bearing an S150A mutation maintained a single PARP1:HPF1 modification site (Figure S3). Considering that the highly similar H1.2 ${ }_{143-158}$ S150A construct was not a PARP1:HPF1 substrate, we hypothesized that the H1.2 ${ }_{142-162}$ secondary modification site is dependent upon the $\mathrm{N}$-terminal cysteine residue. To unambiguously identify the modification site, we incubated the unmodified S150A mutant peptide bearing an $\mathrm{N}$-terminal cysteine and the ADP-ribosylated variant of this peptide with iodoacetamide. Interestingly, while the unmodified S150A mutant could be labeled with iodoacetamide as confirmed by RP-HPLC/MS analysis, the ADP-ribosylated variant of this peptide was resistant to iodoacetamide treatment (Figure 2B and S3). Therefore, the PARP1:HPF1 complex modifies the thiol moiety of $\mathrm{N}$-terminal cysteine residues.

Our discovery that PARP1:HPF1 efficiently modifies N-terminal cysteine side chains is a critical point to consider when preparing ADP-ribosylated proteins via the chemoenzymatic ADPr strategy. All ADP-ribosylated fragments that require an N-terminal cysteine for downstream ligation reactions must maintain a thiol protecting group through the enzymatic ADPr step. Furthermore, the peptide:ADP-ribose linkage must remain stable under conditions required to liberate the free thiol after the peptide ADPr reaction. Considering that serine ADPr is an acidstable modification, an N-terminal thiazolidine (Thz) protection strategy was pursued, as this 
104

105

106

107

108

109

110

111

112

113

114

115

116

117

118

119

120

121

122

123

124

125

126

127

128

129

moiety can be rapidly and quantitatively converted to cysteine in the presence of methoxyamine hydrochloride under acidic conditions ${ }^{24}$. Initial N-terminal Thz H1.2142-162, synthesis efforts revealed that the Thz moiety is not stable during the acyl hydrazide to thioester conversion reaction, as previously reported ${ }^{25}$. We therefore prepared $\mathrm{H} 1.2_{142-162}$ as a C-terminal bis(2sulfanylethyl)amido (SEA) peptide (Figure 2C and S2). While the oxidized SEA group is inert in native chemical ligation reactions, the reduced SEA moiety is highly reactive with small molecule thiols to generate a C-terminal thioester. Thus, the user can selectively deprotect the free N-terminal Thz or the oxidized SEA group (via incubation with $10 \mathrm{mM}$ TCEP) depending on the desired sequential ligation directionality. More importantly, we found that both deprotection strategies are compatible with the ADP-ribose moiety.

ADP-ribosylated H1.2 ${ }_{142-162}$ was prepared by incubating the Thz/reduced SEA peptide with the PARP1:HPF1 complex, and the mono-ADP-ribosylated product purified via RP-HPLC (Figure S2). Next, the peptide was resuspended in a mild oxidation buffer to fully oxidize the SEA moiety, and the Thz deprotection reaction was performed to liberate the $\mathrm{N}$-terminal cysteine (Figure S2). A native chemical ligation reaction with $\mathrm{H1}$.22-141 was carried out and the ligated product (H1.22-162 S150ADPr 1 ) purified via RP-HPLC (Figure S2). An SEA to thioester conversion step was used to generate the H1.22-162 S150ADPr 1 thioester fragment, which was directly employed in a second ligation reaction with H1.2 ${ }_{163-213}$ (Figure S2). Finally, a desulfurization reaction was carried out to convert ligation junction cysteines to native alanine residues and obtain the full-length $\mathrm{H} 1.2$ S150ADPr${ }_{1}$ construct (Figure 2D). A similar synthetic scheme was effective to produce the full-length H1.2 S188ADPr${ }_{1}$ construct (Figure 2E and S4). In this case, the synthetic fragment (amino acids 177-213) was prepared with an N-terminal Thz and C-terminal acid moiety, as a two-piece ligation strategy was sufficient to access the S188 ADPr site (Figure S5). We therefore expect the Thz-based N-terminal cysteine protection strategy will be broadly compatible with our chemoenzymatic peptide ADPr technology and, 
when combined with the C-terminal SEA moiety, will grant synthetic access to many unexplored ADPr sites.

We have previously shown that PARP1 efficiently elongates ADP-ribose chains from monoADP-ribosylated serine residues in the absence of HPF1 ${ }^{12}$. Indeed, this catalytic property of PARP1 is maintained on the full-length, mono-ADP-ribosylated $\mathrm{H} 1.2$ constructs prepared herein. We found that PARP1 catalyzes ADP-ribose chain polymerization from both the S150ADPr 1 and S188ADPr 1 sites to a similar extent in unlabeled NAD ${ }^{+}$and biotinylated NAD ${ }^{+}$ based ADPr assays (Figure 3A and 3B). Importantly, the ADPr activity observed in PARP1 elongation assays represents single ADP-ribose chains emanating from the pre-installed $\mathrm{H} 1.2$ mono-ADPr site, as only trace levels of activity could be detected on the unmodified $\mathrm{H} 1.2$ substrate.

The linker histone C-terminal domain is known to enhance DNA binding affinity ${ }^{26}$. A fluorescence polarization-based 30-mer DNA binding assay was employed to determine if sitespecific serine mono-ADPr impacts the H1:DNA interaction (Figure 3C and Table S1). While an H1.2 construct lacking the C-terminal domain ( $\left.\mathrm{H} 1.2_{2-108}\right)$ exhibited a 50-fold reduction in DNA binding affinity, mono-ADPr did not significantly impact the H1.2:DNA interaction. We next sought to test the possibility that H1.2 poly-ADPr is required to disrupt the H1.2:DNA interface. To this end, the full-length $\mathrm{H} 1.2$ S150ADPr 1 and H1.2 S188ADPr ${ }_{1}$ constructs were incubated with PARP1 and $\mathrm{NAD}^{+}$, and products bearing variable length ADP-ribose chains were isolated via RP-HPLC fractionation. Gel migration and mass analysis of the poly-ADP-ribosylated H1 products showed a chain length distribution ranging primarily from 4-18 ADP-ribose units (Figure S6), and the purified constructs (H1.2 S150ADPr poly and H1.2 S188ADPr poly) were employed in DNA interaction assays. Again, no significant impact on DNA affinity was observed. While these results suggest that $\mathrm{H} 1.2$ poly-ADPr does not directly impact DNA binding activity, it 
should be noted that longer ADP-ribose chain lengths and/or chromatin templates may be

157 required to elicit such an effect.

We next explored the effects of site-specific mono- and poly-ADPr on $\mathrm{H} 1$-induced chromatin compaction. Chromatin array substrates (5 nM) comprising 12 evenly spaced nucleosomes on a single DNA template were incubated with increasing concentrations of the unmodified, monoand poly-ADP-ribosylated H1 constructs (Figure 3D). Native gel shift-based compaction assays revealed that unmodified $\mathrm{H} 1$ constructs abrogated gel migration of all array species at $240 \mathrm{nM}$

164 (4:1 molar ratio of $\mathrm{H} 1$ :nucleosome), indicating a strong compaction effect. In stark contrast, no chromatin compaction was observed in the presence of the poly-ADP-ribosylated $\mathrm{H} 1$ constructs at concentrations as high as $600 \mathrm{nM}$ (10:1 molar ratio of $\mathrm{H} 1.2$ :nucleosome). A more modest effect was observed with mono-ADP-ribosylated $\mathrm{H} 1$ constructs, which maintained their ability to stimulate chromatin compaction albeit at higher concentrations relative to the unmodified protein. Thus, site-specific $\mathrm{H} 1.2$ serine ADPr is sufficient to abrogate its chromatin-compaction activity, and this effect is amplified by ADP-ribose chain elongation.

172 To further characterize H1.2 ADPr and its impact on chromatin structure, H1.2 constructs were

173 incubated with chromatin arrays at a 12:1 molar ratio (an equimolar ratio of H1.2:nucleosome)

174 and chromatin sedimentation velocities were analyzed via analytical ultracentrifugation (Figure

$1753 \mathrm{E}$ and Table S2). Consistent with gel mobility results, the chromatin arrays that were incubated 176 with unmodified $\mathrm{H} 1.2$ displayed the highest sedimentation coefficient $\left(\mathrm{s}_{20, \mathrm{w}}=43.5 \mathrm{~S}\right)$ and thus

177 the greatest level of compaction. Again, we found that mono-ADPr at either the S150 or S188

178 site was sufficient to reduce chromatin compaction levels as evidenced by the reduced

179 sedimentation coefficients $\left(\mathrm{s}_{20, \mathrm{w}}=38.5 \mathrm{~S}\right.$ and $38.6 \mathrm{~S}$, respectively) relative to the unmodified

180 H1.2-treated arrays. These compaction deficiencies were even more pronounced in array

181 samples treated with poly-ADP-ribosylated $\mathrm{H} 1$ constructs, wherein $\mathrm{H} 1.2 \mathrm{~S} 150 \mathrm{ADPr}$ poly and $\mathrm{H} 1.2$ 

measured in the presence of H1.2 S150ADPr poly, H1.2 S188ADPr poly, or the H1.22-108 construct lacking the C-terminal domain were nearly identical. Therefore, poly-ADPr at a single serine site is sufficient to prevent the $\mathrm{H} 1.2 \mathrm{C}$-terminal disordered domain from contributing to chromatin compaction.

In closing, we have developed a strategy to prepare ADP-ribosylated peptides that can be assembled into full-length proteins using sequential native chemical ligation reactions. We found that site-specific serine mono-ADPr on the linker histone $\mathrm{H} 1.2$ is sufficient to induce chromatin decompaction, and that this effect is amplified by ADP-ribose chain elongation. Importantly, our approach allows us to unambiguously attribute these chromatin compaction deficiencies to H1.2 ADPr. The results presented here are consistent with a model wherein $\mathrm{H} 1.2$ serine ADPr induces chromatin relaxation, but additional factors are necessary to displace H1.2 from DNA

195 damage sites. More broadly, our work demonstrates the utility of an expanded semisynthetic

196 toolkit to study site-specific serine ADPr and its impact on protein function and genome 197 structure.

\section{Acknowledgements}

200 We thank Dr. Deepak Nijhawan, Dr. Benjamin Tu and members of the Liszczak laboratory for 201 insightful discussions. We thank Dr. Andrew Lemoff and the UT Southwestern Proteomics Core 202 for technical assistance. This work was supported by grants from the Welch Foundation (I-203920320200401 to G.L.), the Cancer Prevention Research Institute of Texas (RR180051 to G.L.) and 204 the American Cancer Society (UTSW-IRG-17-174-13). G.L. is the Virginia Murchison Linthicum 205 Scholar in Medical Research. 
207 Declaration of interests

208 The authors declare no competing interests.

209

210 Supporting information

211 A detailed description of the materials and methods used in this study can be found in the

212 Supporting Information. Figure S1-S6 contain MS and RP-HPLC characterizations of protein

213 fragments and full-length proteins described in the study, as well as a schematic of the two-

214 piece assembly strategy used to access the H1.2 S188ADPr site. Tables S1 and S2 show full

215 data from fluorescence polarization experiments and analytical ultracentrifugation, respectively.

216 Uncropped gels and blots presented in this study are also included here. 

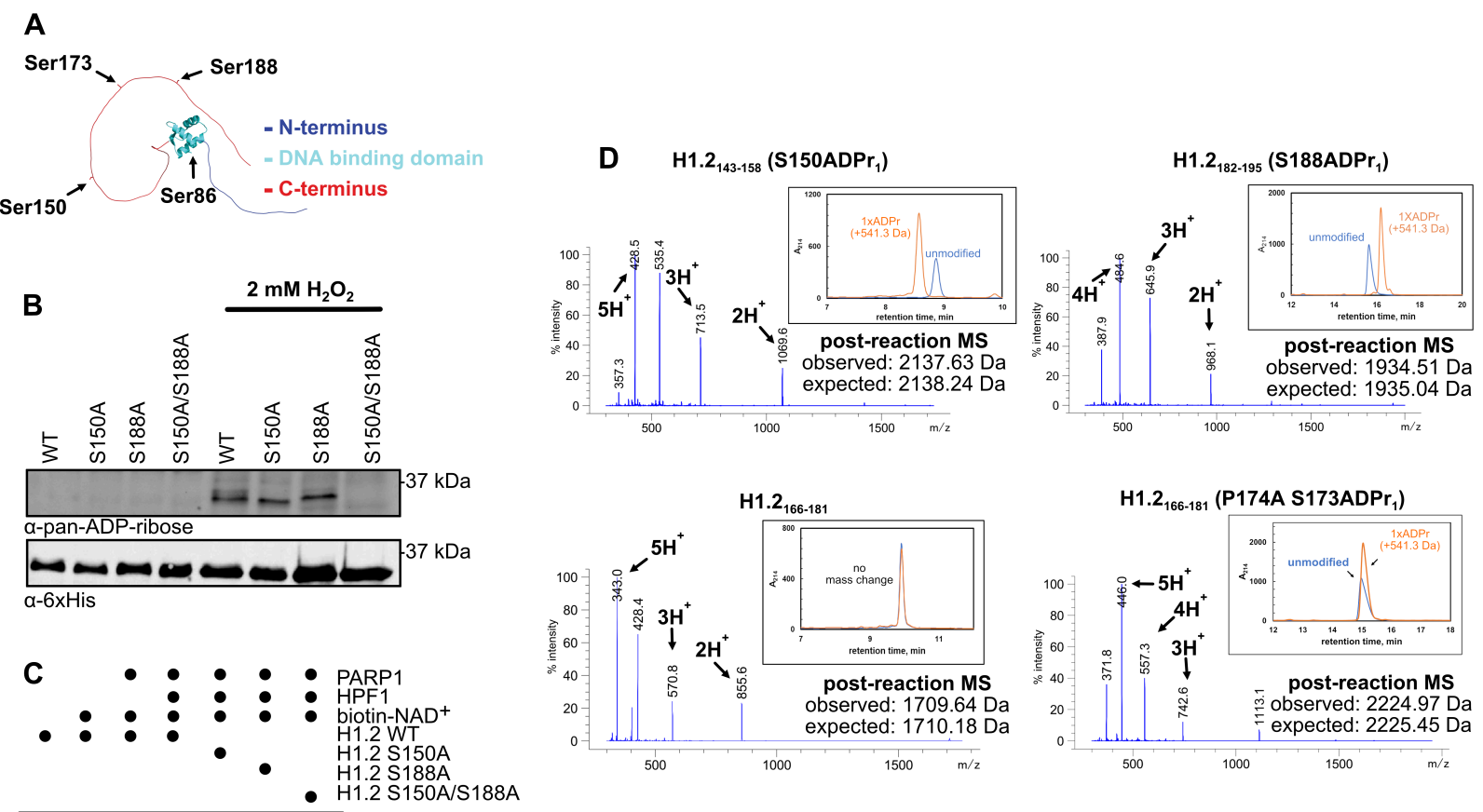

Figure 1. Histone H1.2 S150 and S188 are the main DNA-damage dependent ADP-

ribosylation sites. (A) AlphaFold-predicted three-dimensional structure of full-length $\mathrm{H} 1.2$ with serine residue that occur within a Lys-Ser motif indicated. (B) Western blot analysis of the indicated 6xHis-tagged H1.2 transgenes that were enriched from HEK293T cells via Ni-NTA affinity pre- and post-exposure to hydrogen peroxide $(2 \mathrm{mM}, 15 \mathrm{~min})$. (C) Western blot analysis of reconstituted, biotin-NAD+-based PARP1:HPF1 ADPr assays consisting of the indicated recombinant enzymatic components and full-length H1.2 constructs. (D) RP-HPLC analysis of the indicated synthetic $\mathrm{H} 1.2$ peptide fragments pre- and post-incubation with reconstituted PARP1:HPF1 and NAD ${ }^{+}$. Intact ESI-MS analysis of each post-reaction $\mathrm{H} 1.2$ fragment is shown. 
A

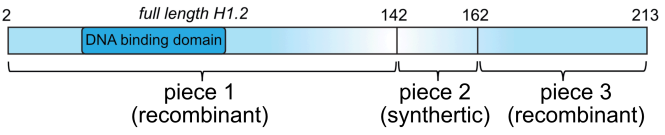

B

H1.2 ${ }_{142-158}(\mathrm{~A} 142 \mathrm{C} / \mathrm{S} 150 \mathrm{~A}) \quad \mathrm{H} 1.2_{142-158} \mathrm{ADPr}_{1}(\mathrm{~A} 142 \mathrm{C} / \mathrm{S} 150 \mathrm{~A})$
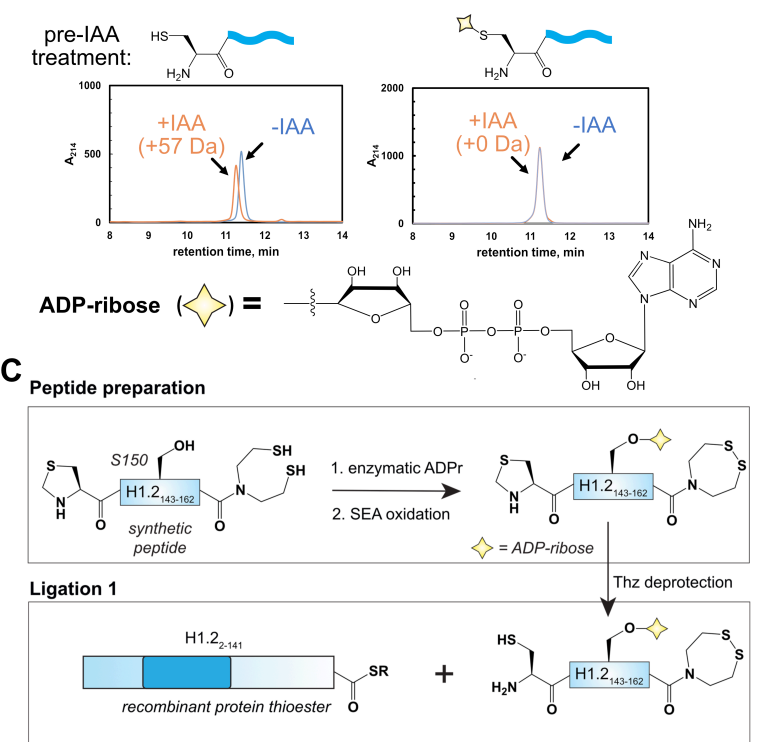

D
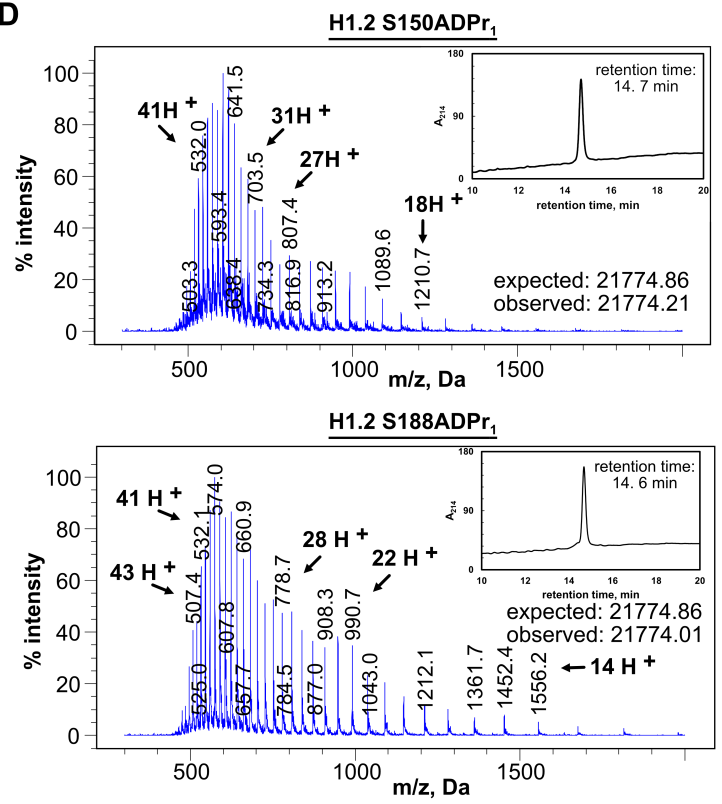

Ligation 2

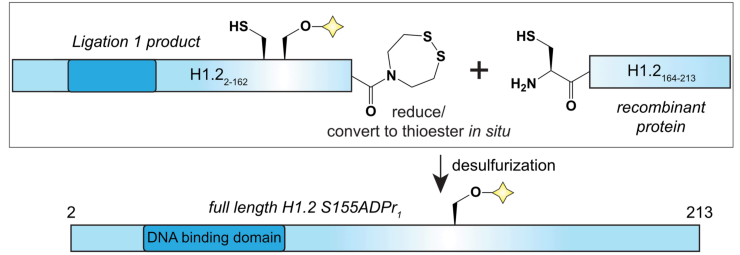

Figure 2. Semi-synthetic preparation of full-length, mono-ADP-ribosylated H1.2

constructs. (A) The three-piece protein assembly strategy to access the H1.2 S150ADPr site.

(B) RP-HPLC analysis of the unmodified and ADP-ribosylated H1.2 ${ }_{142-158}$ (A142C/S150A) peptides pre- and post-iodoacetamide (IAA) treatment. The mass difference post-IAA treatment is indicated. For raw ESI-MS analyses, see Figure S3. (C) Schematic summarizing the semisynthetic route to prepare full-length H1.2 S150ADPr ${ }_{1}$. For similar schematic depicting fulllength H1.2 S150ADPr 1 semisynthetic route, see Figure S4. (D) RP-HPLC and ESI-MS analysis

237 of the full-length $\mathrm{H} 1.2 \mathrm{~S}_{150 A D P r}$ and full-length $\mathrm{H} 1.2 \mathrm{~S}_{188 A D P r}$ proteins. 


\section{A}

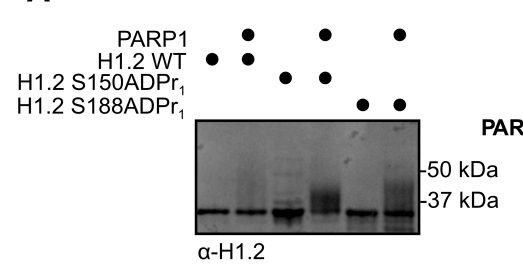

C

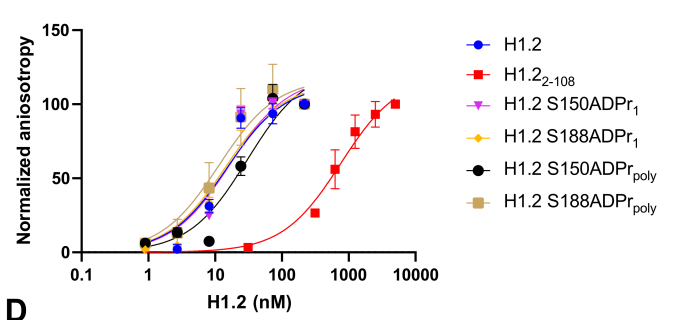

D

B

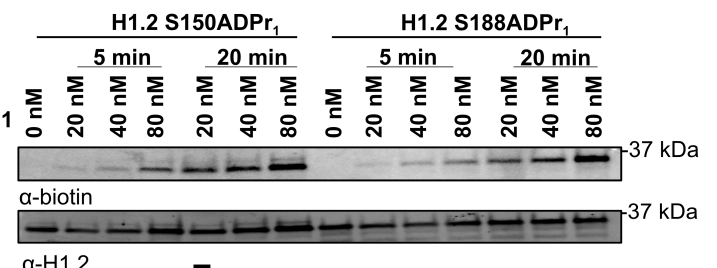

E

\begin{tabular}{|c|c|}
\hline H1.2 construct & $\begin{array}{c}\text { chromatin } \\
\mathbf{S}_{\mathbf{2 0 , w} \text {-value (s) }}\end{array}$ \\
\hline $\mathrm{H} 1.2$ & 43.5 \\
\hline $\mathrm{H} 1.2_{2-108}$ & 35.0 \\
\hline $\mathrm{H} 1.2 \mathrm{~S} 150 \mathrm{ADPr}_{1}$ & 38.5 \\
\hline $\mathrm{H} 1.2 \mathrm{~S} 150 \mathrm{ADPr}_{\text {poly }}$ & 35.2 \\
\hline $\mathrm{H} 1.2 \mathrm{~S} 188 \mathrm{ADPr}_{1}$ & 38.6 \\
\hline $\mathrm{H} 1.2 \mathrm{~S} 188 \mathrm{ADPr}_{\text {poly }}$ & 35.3 \\
\hline
\end{tabular}

H1.2 unmodified [H1.2] / [NCP] 0

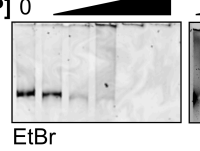

S150ADPr $r_{1} \quad$ S188ADP

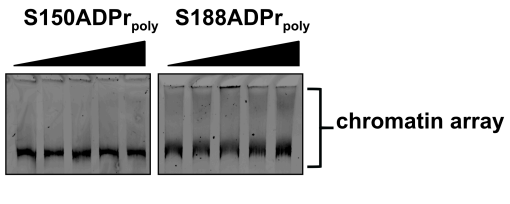
the indicated unmodified or mono-ADP-ribosylated full-length $\mathrm{H} 1.2$ substrate protein. (B) Western blot analysis of PARP1 elongation activity time course on the indicated mono-ADPribosylated full-length $\mathrm{H} 1.2$ substrate in the presence of biotinylated $\mathrm{NAD}^{+}$. (C) Fluorescence

245 polarization assays to evaluate binding affinities of the indicated $\mathrm{H} 1.2$ constructs to a

246 fluorescein-labeled 30 base pair DNA fragment. (D) Native 3\% TBE gel electrophoresis analysis

247 of chromatin arrays ( $5 \mathrm{nM}$ array $=60 \mathrm{nM}$ nucleosome) in the presence of increasing

248 concentrations of the indicated H1.2 construct (120, 240, 480, 960 and $1200 \mathrm{nM}) .(\mathrm{E})$

249 Sedimentation coefficient values $\left(S_{20, w}\right)$ of chromatin arrays (15 nM array $=180 \mathrm{nM}$

250 nucleosome) in the presence of the indicated $\mathrm{H} 1.2$ construct (180 nM) as determined via 251 analytical ultracentrifugation. 


\section{References}

2541 Gupte, R., Liu, Z. \& Kraus, W. L. PARPs and ADP-ribosylation: recent advances linking

255 molecular functions to biological outcomes. Genes Dev 31, 101-126, (2017).

2562 Gibbs-Seymour, I., Fontana, P., Rack, J. G. M. \& Ahel, I. HPF1/C4orf27 Is a PARP-1Interacting Protein that Regulates PARP-1 ADP-Ribosylation Activity. Mol Cell 62, 432442, (2016).

259

3 Bonfiglio, J. J., Fontana, P., Zhang, Q., Colby, T., Gibbs-Seymour, I., Atanassov, I., Bartlett, E., Zaja, R., Ahel, I. \& Matic, I. Serine ADP-Ribosylation Depends on HPF1. Mol Cell 65, 932-940 e936, (2017).

2624 Larsen, S. C., Hendriks, I. A., Lyon, D., Jensen, L. J. \& Nielsen, M. L. Systems-wide Analysis of Serine ADP-Ribosylation Reveals Widespread Occurrence and Site-Specific Overlap with Phosphorylation. Cell Rep 24, 2493-2505 e2494, (2018). Palazzo, L., Leidecker, O., Prokhorova, E., Dauben, H., Matic, I. \& Ahel, I. Serine is the major residue for ADP-ribosylation upon DNA damage. Elife 7, (2018).

2676 Rudolph, J., Roberts, G., Muthurajan, U. M. \& Luger, K. HPF1 and nucleosomes mediate a dramatic switch in activity of PARP1 from polymerase to hydrolase. Elife 10, (2021).

2707 Suskiewicz, M. J., Zobel, F., Ogden, T. E. H., Fontana, P., Ariza, A., Yang, J. C., Zhu,

271 K., Bracken, L., Hawthorne, W. J., Ahel, D., Neuhaus, D. \& Ahel, I. HPF1 completes the 272 PARP active site for DNA damage-induced ADP-ribosylation. Nature 579, 598-602, $273 \quad(2020)$.

2748 Hendriks, I. A., Buch-Larsen, S. C., Prokhorova, E., Elsborg, J. D., Rebak, A., Zhu, K., 275 Ahel, D., Lukas, C., Ahel, I. \& Nielsen, M. L. The regulatory landscape of the human HPF1- and ARH3-dependent ADP-ribosylome. Nat Commun 12, 5893, (2021). 
2779 Leidecker, O., Bonfiglio, J. J., Colby, T., Zhang, Q., Atanassov, I., Zaja, R., Palazzo, L., Stockum, A., Ahel, I. \& Matic, I. Serine is a new target residue for endogenous ADPribosylation on histones. Nat Chem Biol 12, 998-1000, (2016).

28010 Liszczak, G., Diehl, K. L., Dann, G. P. \& Muir, T. W. Acetylation blocks DNA damageinduced chromatin ADP-ribosylation. Nat Chem Biol 14, 837-840, (2018). dynamically controls the PARP1/2 balance between initiating and elongating ADP-ribose modifications. Nat Commun 12, 6675, (2021).

12 Mohapatra, J., Tashiro, K., Beckner, R. L., Sierra, J., Kilgore, J. A., Williams, N. S. \& chromatin remodeling. Elife 10, (2021).

13 Prokhorova, E. et al. Unrestrained poly-ADP-ribosylation provides insights into chromatin regulation and human disease. Mol Cell 81, 2640-2655 e2648, (2021). future. Nat Rev Drug Discov 19, 711-736, (2020).

29215 Bonfiglio, J. J., Leidecker, O., Dauben, H., Longarini, E. J., Colby, T., San SegundoAcosta, P., Perez, K. A. \& Matic, I. An HPF1/PARP1-Based Chemical Biology Strategy Filippov, D. V. Synthetic alpha- and beta-Ser-ADP-ribosylated Peptides Reveal alphaSer-ADPr as the Native Epimer. Org Lett 20, 4140-4143, (2018). Histones Reveals Site-Specific Impacts on Chromatin Structure and Function. J Am Chem Soc 143, 10847-10852, (2021). damage repair. Cell Res 28, 756-770, (2018). 
19 Strickfaden, H., McDonald, D., Kruhlak, M. J., Haince, J. F., Th'ng, J. P. H., Rouleau, M., Ishibashi, T., Corry, G. N., Ausio, J., Underhill, D. A., Poirier, G. G. \& Hendzel, M. J. Poly(ADP-ribosyl)ation-dependent Transient Chromatin Decondensation and Histone Displacement following Laser Microirradiation. J Biol Chem 291, 1789-1802, (2016).

30720 Althaus, F. R. Poly ADP-ribosylation: a histone shuttle mechanism in DNA excision repair. J Cell Sci 102 ( Pt 4), 663-670, (1992).

Azad, G. K., Ito, K., Sailaja, B. S., Biran, A., Nissim-Rafinia, M., Yamada, Y., Brown, D. T., Takizawa, T. \& Meshorer, E. PARP1-dependent eviction of the linker histone H1 mediates immediate early gene expression during neuronal activation. J Cell Biol 217, 473-481, (2018).

31322 Poirier, G. G., de Murcia, G., Jongstra-Bilen, J., Niedergang, C. \& Mandel, P. Poly(ADPribosyl)ation of polynucleosomes causes relaxation of chromatin structure. Proc Natl Acad Sci U S A 79, 3423-3427, (1982).

31623 Zheng, J. S., Tang, S., Qi, Y. K., Wang, Z. P. \& Liu, L. Chemical synthesis of proteins 317 using peptide hydrazides as thioester surrogates. Nat Protoc 8, 2483-2495, (2013).

31824 Bang, D., Pentelute, B. L. \& Kent, S. B. Kinetically controlled ligation for the convergent 319 chemical synthesis of proteins. Angew Chem Int Ed Engl 45, 3985-3988, (2006).

32025 Fang, G. M., Wang, J. X. \& Liu, L. Convergent chemical synthesis of proteins by ligation 321 of peptide hydrazides. Angew Chem Int Ed Engl 51, 10347-10350, (2012).

32226 White, A. E., Hieb, A. R. \& Luger, K. A quantitative investigation of linker histone interactions with nucleosomes and chromatin. Sci Rep 6, 19122, (2016). 
bioRxiv preprint doi: https://doi.org/10.1101/2022.02.17.480967; this version posted February 18,2022 . The copyright holder for this preprint (which was not certified by peer review) is the author/funder. All rights reserved. No reuse allowed without permission. 